\title{
Mineração
}

\section{Avaliação da capacidade de adsorção de vermiculita hidrofóbica em contato direto com óleo}

\author{
Dalila Moreira Silveira \\ Programa de Pós-Graduação em Engenharia Mineral - Escola de Minas - Universidade Federal de Ouro Preto \\ E-mail: lilaquimica@yahoo.com.br \\ Jader Martins \\ Programa de Pós-Graduação em Engenharia Mineral - Escola de Minas - Universidade Federal de Ouro Preto \\ E-mail: jadermar@terra.com.br \\ Tânia Márcia Sacramento Melo \\ Departamento de Química - Instituto de Ciências Exatas e Biológicas - Universidade Federal de Ouro Preto \\ E-mail:tânia@iceb.ufop.br \\ Laurent Frédéric Gil \\ Departamento de Química - Instituto de Ciências Exatas e Biológicas - Universidade Federal de Ouro Preto \\ E-mail: laurent@iceb.ufop.br
}

\section{Resumo}

Com o aumento da necessidade de diminuir ao máximo qualquer tipo de poluição, inúmeras técnicas, métodos e materiais para a retenção de óleos são desenvolvidos. Entre os materiais podem se destacar minerais com a capacidade de adsorver compostos apolares. Nesse caso, especificamente, damos relevância à vermiculita hidrofobizada. Nesse trabalho, a vermiculita hidrofobizada e a vermiculita somente expandida de diferentes granulometrias e de diferentes origens foram testadas quanto à adsorção de um ácido graxo específico: ácido oléico.

Palavras-chave: vermiculita hidrofobizada, compostos apolares, adsorção, materiais adsorventes.

\begin{abstract}
With the increasing need to maximally reduce any type of pollution, countless techniques, methods and materials for oil retention are being developed. Among the materials that stand out are minerals which have a capacity to adsorb non-polar composites. In this case study, relevance is specifically given to hydrofobized vermiculite. The hydrofobized vermiculite and the vermiculite, including different sized particles and different origins, were tested for their adsorption capacity of a fatty acid: specifically, oleic acid.
\end{abstract}

Keywords: hydrofobized vermiculite, non-polar composites, adsoption, material adsorbence. 


\section{Introdução}

A poluição das águas é um problema que requer atenção especial e solução rápida, para os dias atuais. Segundo a Organização dos Estados Americanos (OEA), as atividades de maior contribuição para essa situação são as atividades mineiras e metalúrgicas, pois utilizam um grande volume de água e são responsáveis pela liberação de grandes volumes de resíduos aquosos contendo diversos elementos tóxicos (Rubio \& Tessele, 2002). Muitas são as atividades industriais (mineradoras, siderúrgicas, refinarias, etc.) e de serviços que apresentam problemas de água contaminada com óleo.

Técnicas de tratamento, como precipitação química, troca iônica e degradação biológica, são métodos usados com o objetivo de ajustar as propriedades da água de acordo com a política ambiental e promover seu descarte na natureza de acordo com essas políticas. Também são utilizados tratamentos convencionais mecânicos para limpeza de águas poluídas, que não são muito eficientes, porém materiais de ação adsorvente, produtos mais econômicos e de maior eficácia vêm sendo empregados com intuito de substituir essas técnicas tradicionais.

Esses materiais adsorventes são sólidos porosos, naturais, que possuem afinidade específica para determinado composto e são desenvolvidos para uso industrial, na recuperação de solventes, em fracionamento de misturas de gases, bem como em outras aplicações. Entre esses materiais comerciais se encontram uma variedade de argilas, madeiras, carvão ativado, géis, alumina e silicatos.

Nesse trabalho, foi utilizado, como material adsorvente, diferentes tipos de vermiculita, um argilomineral que, após tratamentos térmicos e químicos, adquire características que a torna hidrofóbica e um excelente adsorvente de compostos orgânicos.

\section{Materiais}

Utilizaram-se, nesse trabalho, vermiculitas de duas localidades e com dois tipos de granulometria, constituindo um total de 6 amostras de vermiculitas. As amostras originais, ou seja, sem nenhum tratamento, foram fornecidas pela empresas Brasil Minérios (Goiás) e Eucatex (Piauí) e foram designadas segundo sua procedência e granulometria, como:

VEFG-VermiculitaExpandidaFinadeGoiás. VEFP-Vermiculita Expandida Fina do Piaú. VEMG - Vermiculita Expandida Micro de Goiás.

VHFG - Vermiculita Hidrofóbica Fina de Goiás.

VHFP - Vermiculita Hidrofóbica Fina do Piauí.

VHMG - Vermiculita Hidrofóbica Micro de Goiás.

As amostras de vermiculita foram classificadas segundo sua granulometria em fina e micro pela empresa que as forneceram. A granulometria da vermiculita fina varia entre 2,0 e 1,0 mm e a granulometria da vermiculita micro varia entre 1,0 e $0,5 \mathrm{~mm}$. Esses materiais não são considerados os produtos nobres da extração de vermiculita, sendo considerados, portanto, como materiais de baixo custo. As amostras de vermiculita hidrofobizadas foram obtidas segundo a patente de invenção 39004025 (Martins, 1991).

\section{Métodos}

\section{Testes de Adsorção (Quantificação de Óleo)}

Os testes de adsorção foram realizados no Departamento de Química da Universidade Federal de Ouro Preto. A partir de adaptações, seguiu-se a metodologia de quantificação de óleo em tela utilizada pela Petrobras.

\section{Procedimento experimental}

Em um béquer de $250 \mathrm{~mL}$ foi adicionado aproximadamente $50 \mathrm{~mL}$ de ácido oléico com massa conhecida. Pesaramse a tela e o adsorvente. Adicionou-se a tela com o adsorvente no béquer com ácido oléico. Esperou-se um tempo determinado para o contato entre adsorvente e óleo e, também, o tempo para escoamento do excesso de ácido oléico. Após este tempo de escoamento, realizou-se a pesagem da tela com adsorvente e ácido oléico. Para obtenção da quantidade de ácido oléico retido na tela, procedeu-se o mesmo experimento com a tela vazia.

A tela utilizada, nesse sistema, foi uma tela de aço inox com aberturas de $0,147 \mathrm{~mm}$. Essa metodologia de quantificação de óleo em tela foi adaptada da metodologia utilizada pelo CENPES, Centro de Pesquisas e Desenvolvimento Leopoldo A. Miguez de Mello da Petrobras. (Mauro, 2001).

\section{Resultados}

Todos os testes de adsorção foram realizados em triplicata e, com os dados obtidos, foi aplicado o teste Q para rejeição de dados, utilizando 95\% de confiança. O teste Q é uma ferramenta estatística utilizada para descartar ou conservar dados que não apresentam uma certa semelhança como os demais dados analisados.

Para esses testes de adsorção, foram utilizados os tempos de contato da vermiculita com o ácido oléico iguais a 0,2; 0,3; $1 ; 5 ; 30$ e 120 minutos. E o tempo para escoamento (repouso) do ácido oléico foi de 5, 30 e 60 minutos. O tempo de escoamento representa um tempo para que ocorra o escoamento do excesso de ácido oléico que possa estar sobre a vermiculita ou sobre a tela. Para a realização dos testes de adsorção desse sistema, foi utilizado $0,500 \mathrm{~g}$ de adsorvente. Os resultados, para esse estudo, são mostrados nas Tabelas 1, 2, 3 e nas Figuras 1,2 e 3 .

\section{Cinética: vermiculita fina do Piauí}

A Tabela 1 apresenta a quantidade de ácido oléico adsorvido por 1,00g de 
Dalila Moreira Silveira et al.

VEFP e VHFP, em diferentes tempos de repouso e de contato. A Figura 1 ilustra, graficamente, os dados da Tabela 1.

\section{Cinética: vermiculita fina de Goiás}

A Tabela 2 apresenta os valores da quantidade de ácido oléico adsorvido por 1,00g de VEFG e VHFG e a Figura 2 mostra a representação desses valores no gráfico.

\section{Cinética: vermiculita micro de Goiás}

A Tabela 3 apresenta os valores da quantidade de ácido oléico adsorvido por 1,00g de VEMG e VHMG e a Figura 3 mostra a representação desses valores no gráfico.

\section{Discussão}

A Tabela 1 faz uma comparação entre a VEFP e a VHFP com relação à quantidade de ácido oléico adsorvido, em diferentes tempos de contato e repouso. Para a amostra de VEFP, percebe-se que se atinge, rapidamente, o equilíbrio de adsorção com a variação do tempo de contato entre a vermiculita e o ácido oléico. Para os três tempos de repouso, a partir de 0,3 minutos de contato entre vermiculita e ácido oléico, não ocorre um aumento significativo da quantidade máxima adsorvida. A partir de 0,3 minutos de contato, observam-se um aumento de $19 \%$ para VEFP, em 30 minutos de repouso, e um aumento de $41 \%$ para VHFP em 5 minutos de repouso.

A VEFP apresenta um aumento de $37 \%$ na quantidade de ácido oléico adsorvido, em 5 minutos de repouso, e um aumento de $16 \%$, em 60 minutos de repouso. Já a VHFP apresenta um crescimento contínuo da quantidade de ácido oléico adsorvido com o aumento do tempo de contato. Esse aumento da quantidade de ácido oléico adsorvida atinge o máximo de 50\%, em 5 minutos e em 30 minutos de repouso, e $48 \%$ em 60 minutos de repouso.
Tabela 1 - Quantidade de ácido oléico adsorvido em função do tempo para a vermiculita fina do Piauí.

\begin{tabular}{|c|c|c|c|c|c|c|}
\hline \multirow{2}{*}{$\begin{array}{c}\text { Tempo de } \\
\text { contato } \\
\text { (min.) }\end{array}$} & \multicolumn{6}{|c|}{ Tempo de repouso } \\
\hline & $5 \mathrm{~min}$. & $30 \mathrm{~min}$. & $60 \mathrm{~min}$. & $5 \mathrm{~min}$. & $30 \mathrm{~min}$. & $60 \mathrm{~min}$. \\
\hline 0,2 & 2,704 & 2,571 & 2,666 & 2,408 & 2,56 & 3,226 \\
\hline 0,3 & 3,219 & 3,315 & 3,266 & 3,305 & 3,186 & 3,64 \\
\hline 1,0 & 4,131 & 4,286 & 4,163 & 3,592 & 3,545 & 3,656 \\
\hline 5,0 & 4,611 & 4,344 & 4,341 & 3,677 & 3,725 & 3,677 \\
\hline 30,0 & 4,957 & 4,618 & 4,494 & 3,771 & 3,746 & 3,739 \\
\hline 120,0 & 5,429 & 5,119 & 5,182 & 3,868 & 3,928 & 3,871 \\
\hline \multicolumn{7}{|c|}{ VHFP - AO adsorvido $\mathrm{g} / \mathrm{g}$} \\
\hline
\end{tabular}

Tabela 2 - Quantidade de ácido oléico adsorvido em função do tempo para a vermiculita fina de Goiás.

\begin{tabular}{|c|c|c|c|c|c|c|}
\hline \multirow{2}{*}{$\begin{array}{c}\text { Tempo de } \\
\text { contato } \\
\text { (min.) }\end{array}$} & \multicolumn{6}{|c|}{ Tempo de repouso } \\
\hline & $5 \mathrm{~min}$. & $30 \mathrm{~min}$. & $60 \mathrm{~min}$. & $5 \mathrm{~min}$. & $30 \mathrm{~min}$. & $60 \mathrm{~min}$. \\
\hline 0,2 & 3,441 & 3,505 & 3,429 & 3,293 & 3,341 & 2,822 \\
\hline 0,3 & 3,751 & 3,594 & 3,533 & 3,402 & 3,538 & 3,184 \\
\hline 1,0 & 3,968 & 3,732 & 3,68 & 3,464 & 3,567 & 3,395 \\
\hline 5,0 & 4,04 & 3,964 & 3,782 & 3,615 & 3,669 & 3,485 \\
\hline 30,0 & 4,054 & 4,003 & 3,873 & 3,642 & 3,793 & 3,495 \\
\hline 120,0 & 4,073 & 4,026 & 3,972 & 3,815 & 3,93 & 3,683 \\
\hline \multicolumn{7}{|c|}{ VHFG - AO adsorvido $\mathrm{g} / \mathrm{g}$} \\
\hline
\end{tabular}

Tabela 3 - Quantidade de ácido oléico adsorvido em função do tempo para a vermiculita micro de Goiás.

\begin{tabular}{|c|c|c|c|c|c|c|}
\hline \multirow{2}{*}{$\begin{array}{l}\text { Tempo de } \\
\text { contato } \\
\text { (min.) }\end{array}$} & \multicolumn{6}{|c|}{ Tempo de repouso } \\
\hline & $5 \mathrm{~min}$. & $30 \mathrm{~min}$. & $60 \mathrm{~min}$. & $5 \mathrm{~min}$. & $30 \mathrm{~min}$. & $60 \mathrm{~min}$. \\
\hline 0,2 & 2,553 & 2,494 & 2,147 & 2,568 & 2,484 & 2,584 \\
\hline 0,3 & 2,657 & 2,593 & 2,467 & 2,704 & 2,682 & 2,602 \\
\hline 1,0 & 3,03 & 2,904 & 2,507 & 2,771 & 2,91 & 2,776 \\
\hline 5,0 & 3,428 & 3,203 & 2,881 & 2,832 & 2,923 & 2,866 \\
\hline 30,0 & 3,462 & 3,372 & 3,353 & 3,047 & 2,94 & 2,946 \\
\hline 120,0 & 3,789 & 3,421 & 3,554 & 3,246 & 3,452 & 3,309 \\
\hline \multicolumn{7}{|c|}{ VHMG - AO adsorvido g/g } \\
\hline
\end{tabular}


Essa diferença no comportamento das amostras de vermiculita citadas pode ser explicada da seguinte forma: a VEFP possui aberturas entre suas camadas, sendo essas aberturas, às vezes, largas, mas, também, podendo ser muito estreitas, ou seja, elas não se apresentam uniformes, dificultando, dessa forma, a entrada do ácido oléico no seu interior. A VHFP, além de possuir as aberturas não uniformes, ainda possui os sítios provenientes do agente hidrofobizante. Esses sítios são responsáveis pela adsorção imediata por se encontrar na superfície do mineral, mas, também, são responsáveis pela adsorção lenta, pois esses sítios podem estar localizados entre as aberturas das camadas, formando filamento entre as intercamadas, dificultando ainda mais a entrada do ácido oléico nas aberturas. Outra justificativa para a melhor capacidade de adsorção da VHFP, nesse estudo, é a maior superfície específica desse material 6,012 $\mathrm{m}^{2} / \mathrm{g}$ quando comparado a VEFP 3,976 m²/g.

Para as amostras de vermiculita originadas de Goiás mostradas na Tabela 2, não foi possível observar, nitidamente, um aumento muito grande na quantidade máxima de ácido oléico adsorvido observada para a vermiculita originada do Piauí. Para a amostra de VHFG, o aumento na quantidade de ácido oléico adsorvida foi em torno de 15\% para os três tempos de repouso. Para a VEFG, o mesmo valor de porcentagem de ácido oléico adsorvido, em torno de 15\%, foi observado para os tempos de repouso iguais a 5' e 30’. O baixo valor de ácido oléico adsorvido pela VHFG, em relação a VHFP, pode ser justificado pela menor área superficial dessa amostra $4,187 \mathrm{~m}^{2} / \mathrm{g}$. Observa-se que a superfície específica da VEFG $\left(4,632 \mathrm{~m}^{2} / \mathrm{g}\right)$ é maior que a superfície específica da VHFG (4,187 m²/g), porém o tamanho médio dos poros da VHFG (99,70 Å) é maior que o tamanho médio dos poros da VEFG (94,73Å). Deste modo, a maior capacidade de adsorção da VHFG com relação a VEFG se deve, não pela superfície específica, mas pelo tamanho médio dos seus poros, que, desta forma, proporcionam a entrada do ácido oléico por maiores cavidades.

Para as amostras de vermiculita micro de Goiás mostradas na Tabela 3, também não foi possível observar, nitidamente, a diferença da quantidade máxima de adsorção observada para a vermiculita originada do Piauí. Na VEMG, observa-se uma certa saturação da quantidade de ácido oléico adsorvido, sendo que o aumento da quantidade de ácido oléico adsorvido não aumenta muito com o aumento do tempo de contato da tela com o ácido oléico. Para a VHMG, a quantidade de ácido oléico adsorvido supera a VEMG, mas não é um valor muito superior.

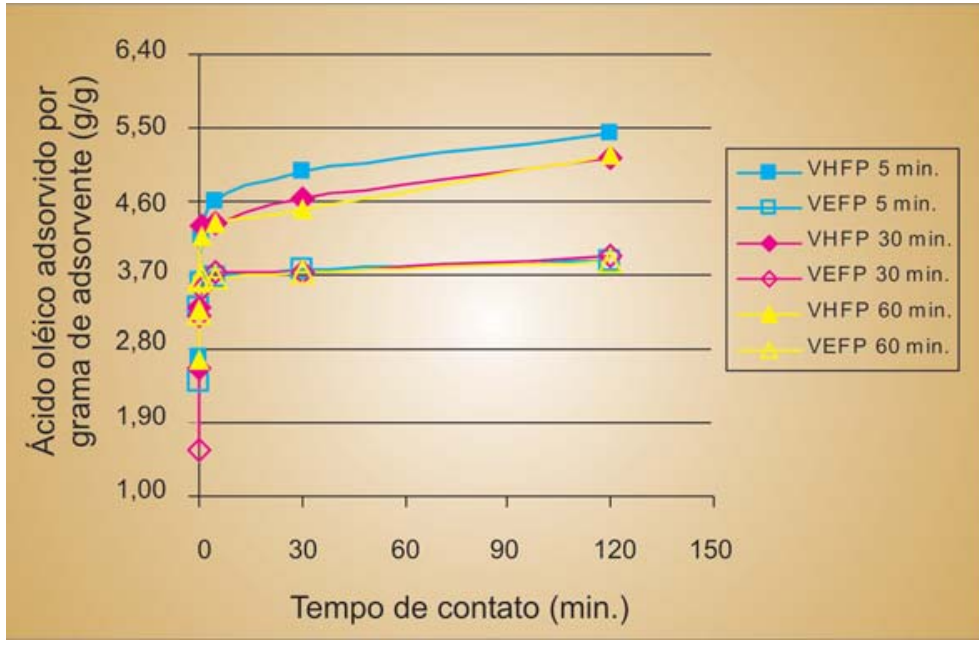

Figura 1 - Comportamento da vermiculita fina do Piauí quando em contato direto com ácido oléico.

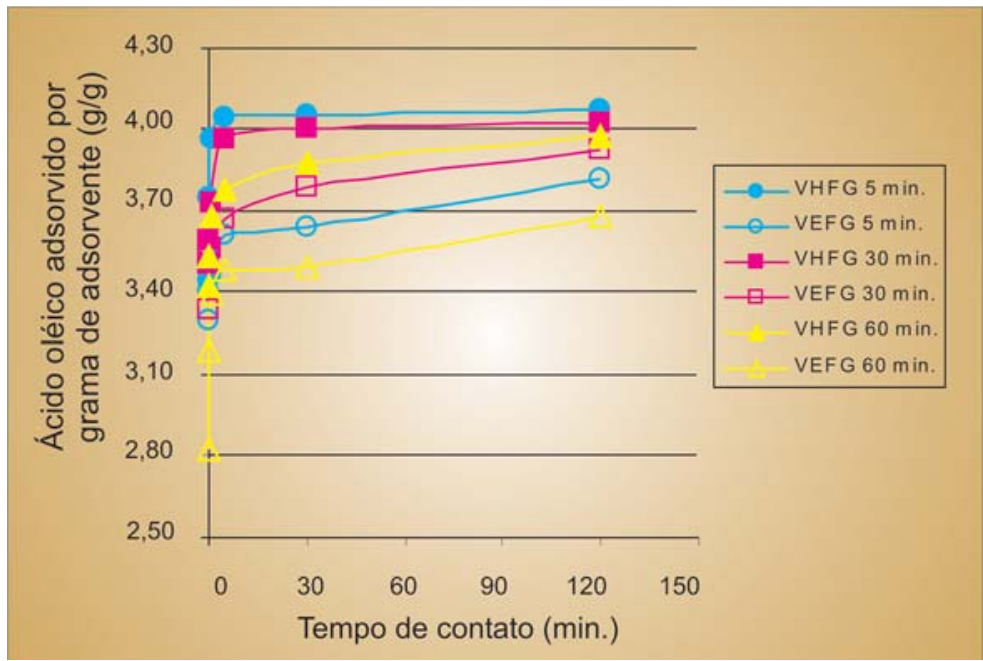

Figura 2 - Comportamento da vermiculita fina de Goiás quando em contato direto com ácido oléico.

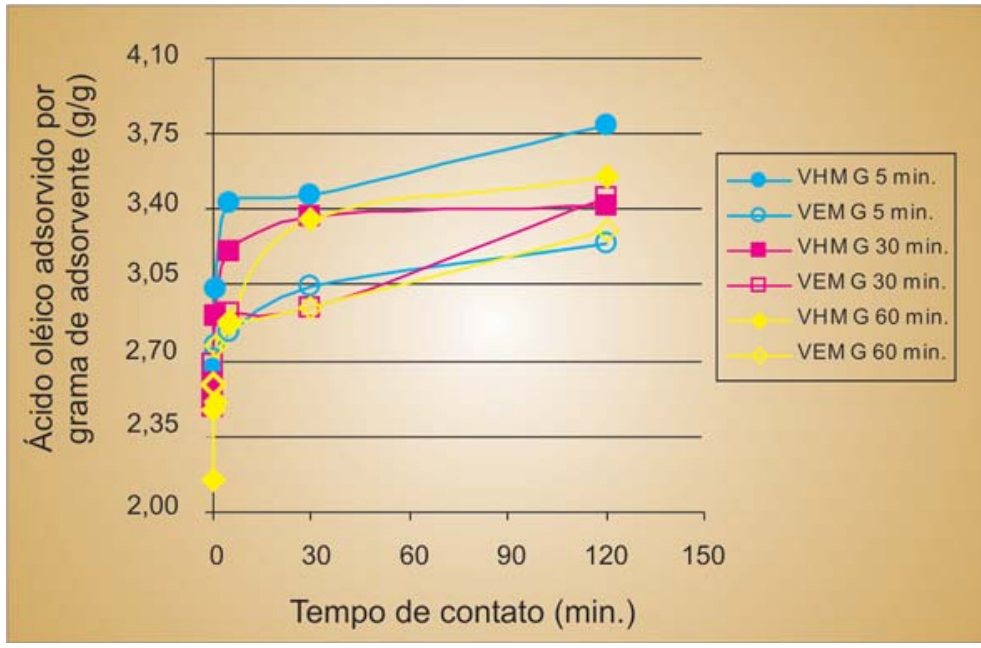

Figura 3 - Comportamento da vermiculita micro de Goiás quando em contato direto com ácido oléico. 


\section{Conclusões}

No contato direto da vermiculita com óleo, VHFP apresentou uma maior capacidade de adsorção em relação às outras vermiculitas. As vermiculitas micro são menos eficazes que as vermiculitas finas. As vermiculitas somente expandidas adsorveram menor quantidade de ácido oléico e atingiram a saturação mais rapidamente que as vermiculitas hidrofobizadas.

Em todos os tempos de contato, as vermiculitas hidrofóbicas apresentaram uma maior adsorção de ácido oléico, quando comparadas às vermiculitas somente expandidas.

\section{Agradecimentos}

Os autores agradecem à CAPES, pela concessão de bolsa de estudo, à UFOP e à PPGEM pela estrutura oferecida para a realização do trabalho.

\section{Referências} bibliográficas

GRIM, R. E. Clay mineralogy. 2. ed. New York: McGraw-Hill, 1968. 596p.

MARTINS, J. Processo aperfeiçoado de hidrofobização de vermiculita expandida. BR $n^{\circ}$ PI 900405. 8 ago.1990, 25 fev. 1991

MAURO, C.A. Critérios técnicos para aquisição de produtos absorventes de óleo - recomendações do Centro de Pesquisas e Desenvolvimento Leopoldo A. Miguez de Mello - Comunicação Técnica. Anexo I. Rio de Janeiro, dez. 2001.

RUBIO, J., TESSELE, F. Processos para o tratamento de efluentes na mineração. In: LUZ, A.B. et al. (Ed.). Tratamento de minérios. Rio de Janeiro: CETEM, 2002. p.639-700.

SILVEIRA, D. M. Adsorção de um ácido graxo utilizado em flotação por vermiculita hidrofóbica. Ouro Preto: PPGEM/UFOP, 2005. $124 \mathrm{f}$. (Dissertação de Mestrado).

Artigo recebido em 13/09/2005 e aprovado em 19/06/2006. 